\title{
Relationship Between Localized Acquired Resistance (LAR) and the Hypersensitive Response (HR): HR Is Necessary for LAR to Occur and Salicylic Acid Is Not Sufficient to Trigger LAR
}

\author{
Laurent Costet, Sylvain Cordelier, Stéphan Dorey, Fabienne Baillieul, Bernard Fritig, and \\ Serge Kauffmann \\ Institut de Biologie Moléculaire des Plantes du C.N.R.S., Université Louis Pasteur. 12, rue du Général \\ Zimmer, 67084 Strasbourg, France \\ Accepted 11 April 1999.
}

In tobacco plants reacting hypersensitively to pathogen infection, localized acquired resistance (LAR) is induced in a sharp zone surrounding hypersensitive response (HR) lesions. Using a fungal glycoprotein inducing HR and LAR when infiltrated at $50 \mathrm{nM}$ into tobacco leaves, we have shown previously that a plant signal(s) is released by $\mathrm{HR}$ cells and diffuses to induce LAR. Here we address two questions: does LAR occur when HR is not induced, and is salicylic acid the (or one of the) mobile LAR signal? We found that application to tobacco leaves of $0.25 \mathrm{nM}$ glycoprotein triggered defense responses without $H R$ and without an $\mathrm{H}_{2} \mathrm{O}_{2}$ burst. The analyzed responses include changes in expression of $O$-methyltransferase (OMT), 3hydroxy-3-methylglutarylCoA reductase, pathogenesisrelated (PR) proteins, and changes in levels of the signal salicylic acid. No defense responses and no increased resistance to tobacco mosaic virus infection were found beyond the elicitor-infiltrated tissue, providing strong evidence that there is no LAR without HR. Treatments of NahG tobacco leaves with $50 \mathrm{nM}$ elicitor induced the HR and, in the sharp zone surrounding the HR lesion, a strong activation of OMT and of basic PR proteins, but not of acidic PR-1 proteins. This indicates that a signal different from salicylic acid is diffusing.

Additional keywords: hydrogen peroxide, Nicotiana tabacum, Phytophthora megasperma.

The hypersensitive response (HR) is an efficient disease resistance mechanism of plants to infection by pathogens (Goodman and Novacky 1994). Phenotypically, HR results in plant cell death occurring at the site of pathogen penetration. Acquired resistance is also induced both locally and systemi-

Corresponding author: Serge Kauffmann; Address: IBMP-CNRS, 12 rue du Général Zimmer, 67084 Strasbourg, France;

Telephone: +33-(0)388 41 7271; Fax: +33-(0)388 61 4442;

E-mail: serge.kauffmann@ibmp-ulp.u-strasbg.fr

Current address of Fabienne Baillieul: Université de Reims, Champagne-Ardenne, Laboratoire de Biologie et Physiologie Végétales, UFR Sciences, Moulin de la Housse, BP 1039, 51687 Reims cedex 2, France. cally. In the early 1960s, Ross (1961a) observed that a high degree of resistance to challenge virus inoculation developed in a 1- to 2-mm zone surrounding each tobacco mosaic virus (TMV)-induced local lesion on hypersensitive Samsun NN tobacco leaves. He called this phenomenon localized acquired resistance (LAR), and also (Ross 1961b) observed that systemic acquired resistance (SAR) occurs beyond the LAR zone, i.e., in tissue distant from lesions and also in tissue of noninoculated leaves. Many studies have shown that SAR provides a low, though significant, level of resistance against a broad range of pathogens, and that only a subset of those defense responses expressed locally (including HR and LAR zones) are triggered in SAR tissues (Ryals et al. 1996). A model was proposed in which pathogen restriction is achieved by the combined effects of HR and LAR (Dorey et al. 1997), while SAR functions as a mechanism potentiating defense responses in noninfected plant tissues (Ryals et al. 1996).

Defense responses induced locally include a broad spectrum of antimicrobial proteins, such as pathogenesis-related (PR) proteins (Fritig et al. 1998), and metabolites deriving from secondary metabolic pathways, such as the sesquiterpenoid (Stoessl et al. 1976) and phenylpropanoid (Nicholson and Hammerschmidt 1992) pathways. Defense response expression is regulated in a spatio-temporal manner and involves various plant signals (Hammond-Kosack and Jones 1996; Kombrink and Somssich 1995). Among these signals, salicylic acid (SA) and hydrogen peroxide $\left(\mathrm{H}_{2} \mathrm{O}_{2}\right)$ have been shown to play a crucial role in establishment of both local and systemic defense responses (Alvarez et al. 1998; Delaney et al. 1994; Draper 1997; Levine et al. 1994; Schneider et al. 1996).

Despite the important role of LAR in defense, it is only recently that strategies have been developed to uncover its properties and characteristics. We have shown previously that infiltration into tobacco leaves of a fungal glycoprotein triggers the HR and LAR (Dorey et al. 1997). The elicitor-infiltrated tissue is called HR zone 1 and the surrounding tissue, about 5 $\mathrm{mm}$ in width, is called LAR zone 2 . Zone 1 undergoes HR cell death accompanied by a strong $\mathrm{H}_{2} \mathrm{O}_{2}$ burst (Dorey et al. 1998). However, before cell death occurs, SA accumulates and expression of genes involved in secondary metabolisms is rapidly stimulated. Among these, referred to as class I genes, are 
the $O$-methyltransferase (OMT) genes of the phenylpropanoid pathway and the 3-hydroxy-3-methylglutarylCoA reductase (HMGR) genes of the sesquiterpenoid pathway. Zone 2, in which no cell death and no $\mathrm{H}_{2} \mathrm{O}_{2}$ burst occur, exhibits strong defense responses including stimulation of class I genes and of PR protein genes referred to as class II genes and SA production. It was further shown that a plant signal(s), but not the elicitor, was diffusing out of HR zone 1 to induce LAR (Dorey et al. 1997).

An open question was whether the LAR signal(s) was released exclusively by plant cells undergoing HR or whether it could be released by cells expressing defense responses without HR. In order to address this question, we decreased the elicitor doses applied to tobacco leaves until no HR symptoms were induced and analyzed expression of various defense responses in treated zone 1 and surrounding zone 2 tissues. Here, we show that a non-HR dose of elicitor triggers a broad spectrum of defense responses localized to the infiltrated zone 1 , and that no increased resistance to TMV infection occurred in the surrounding zone 2. From these results we conclude that there is no LAR when HR is not induced. Using NahG tobacco plants, we further show that a signal different from SA is diffusing from HR zone 1 to LAR zone 2.

\section{RESULTS}

\section{Determination of a threshold level of elicitor concentration} to induce the HR.

Routinely, $50 \mathrm{nM}$ glycoprotein is infiltrated into tobacco leaves to induce the HR. Under these conditions, necrotic symptoms are restricted to the infiltrated tissue and a bright blue fluorescence surrounding the lesion becomes visible under UV light (Fig. 1). Fluorescence indicates tissue exhibiting LAR (Dorey et al. 1997). The HR was still induced when doses in concentrations as low as $1 \mathrm{nM}$ were applied. Symptomless tissue, indistinguishable from tissue infiltrated with water as control, was observed in a reproducible manner after infiltration of $0.25 \mathrm{nM}$ glycoprotein (Fig. 1).

Though symptomless, tissue infiltrated with $0.25 \mathrm{nM}$ glycoprotein could still contain invisible, micro-HR lesions. Thus, we monitored cell death with the Evans blue leaf disk

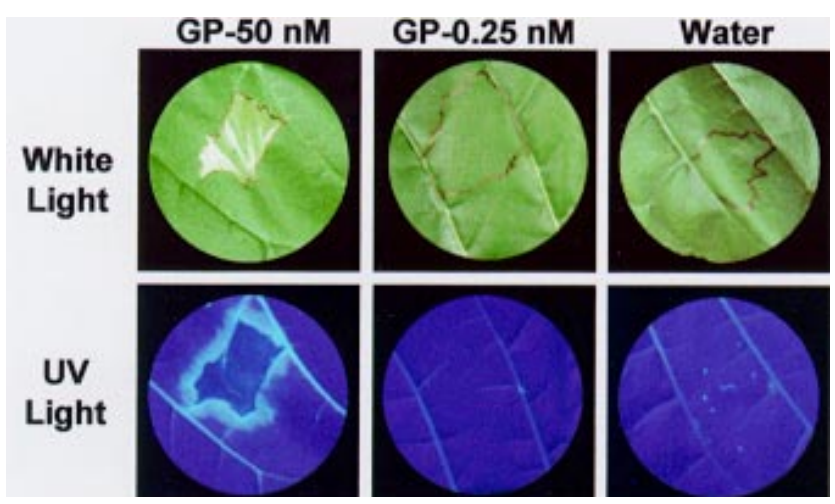

Fig. 1. Symptoms induced on a tobacco leaf by the infiltration of either 50 or $0.25 \mathrm{nM}$ glycoprotein (GP) elicitor. A tobacco leaf was infiltrated with 50 and $0.25 \mathrm{nM}$ GP and water as a control. Leaf disks were punched out 2 days after treatment to photograph symptoms under white and UV light. assay. No increased dye uptake was measured when leaves were infiltrated with $0.25 \mathrm{nM}$ glycoprotein or water as negative control (Fig. 2A, closed triangles and open circles, respectively). Tissue infiltrated with $50 \mathrm{nM}$ glycoprotein as positive control accumulated the vital dye (Fig. 2A, closed circles) indicating cell death. Cell death was further investigated in situ with trypan blue that accumulates in dead cells. Application of $50 \mathrm{nM}$ glycoprotein induced a strong blue staining localized to treated tissue, while tissue infiltrated with $0.25 \mathrm{nM}$ glycoprotein or water remained colorless (Fig. 2B, $\times 0.5$ magnification panel). Only a negligible number of blue spots were counted in the latter tissue (Fig. 2B, arrow in the $\times 50$ magnification panel). No difference between $0.25 \mathrm{nM}$ glycoprotein-treated and water-treated tissues was clearly evidenced. Taken together, the data indicated that the $0.25 \mathrm{nM}$ glycoprotein treatment did not induce HR cell death.

\section{A non-HR dose of elicitor activates defense genes in zone 1.}

Although a non-HR dose of glycoprotein did not trigger $\mathrm{HR}$, it could still induce defense responses. Expression of OMT, HMGR, and PR-5 genes was analyzed in leaves infiltrated with various glycoprotein doses. Infiltrated tissues were sampled $9 \mathrm{~h}$ after treatment to analyze OMT and HMGR gene expression and $48 \mathrm{~h}$ after treatment to analyze PR-5 gene expression, since earlier work (Baillieul et al. 1995) had shown
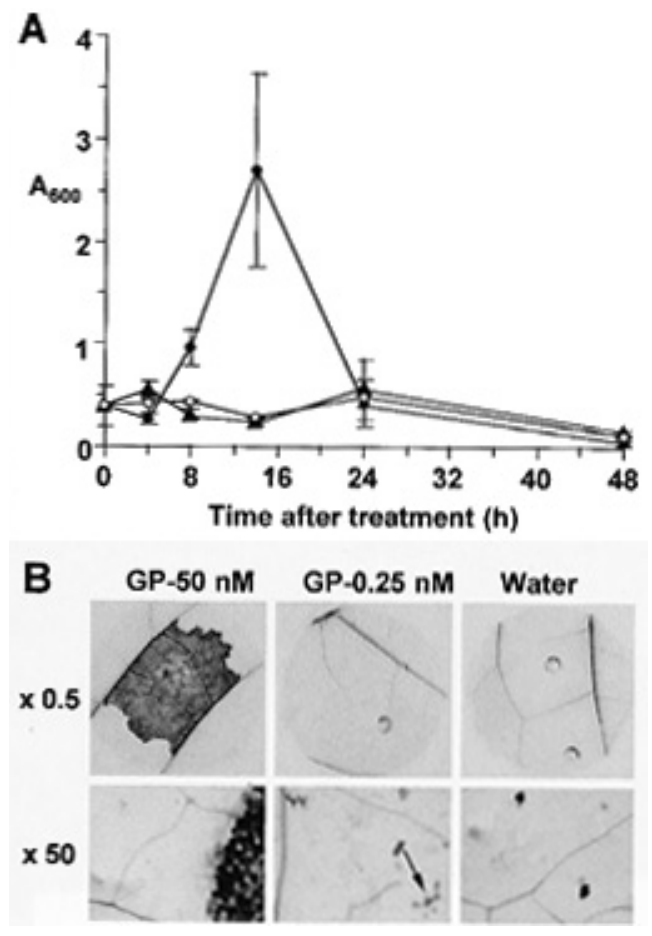

Fig. 2. Cell death in tobacco leaves infiltrated with either a non-HR (hypersensitive response) or HR dose of elicitor. Leaves were infiltrated with either 0.25 or $50 \mathrm{nM}$ glycoprotein (GP) or water as control. A, Cell death evaluated by the uptake of Evans blue quantified by spectrophotometry. Three disks from three treated leaves were used for each assay. Each time point represents the mean of two independent experiments and the standard deviation. Closed triangles, $0.25 \mathrm{nM}$ glycoprotein; closed circles, $50 \mathrm{nM}$ glycoprotein; open circles, water treatment. B, Cell death evaluated in situ with the trypan blue assay. Staining was performed $24 \mathrm{~h}$ after treatments. Leaf disks are shown at two different magnifications $(\times 0.5$ and $\times 50)$. The arrow indicates a dead cell. 
that maximum gene expression occurred $9 \mathrm{~h}$ after treatment for class I genes and $48 \mathrm{~h}$ after treatment for class II genes. Decreasing glycoprotein doses resulted in decreased steady state levels of OMT, HMGR, and PR-5 mRNAs (Fig. 3). In this experiment, only the $50 \mathrm{nM}$ dose induced HR. The results clearly showed that a non-HR dose of glycoprotein stimulated defense gene expression and that very low doses of glycoprotein induced only very low levels of defense gene expression.

\section{A non-HR dose of elicitor does not activate defense responses in zone 2.}

Defense response expression was analyzed in zone 2 of leaves infiltrated with a non-HR dose of glycoprotein. It was

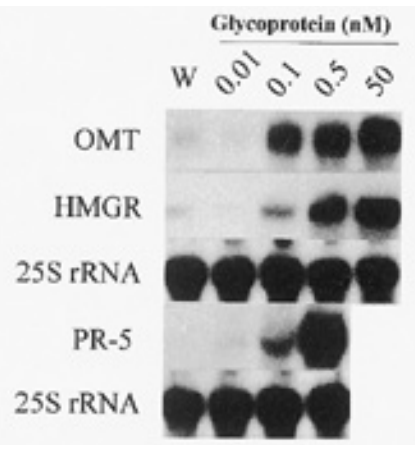

Fig. 3. Dose-dependent expression of defense genes in elicitor-infiltrated zone 1 . Tobacco leaves were infiltrated with either $0.01,0.1,0.5$, or 50 $\mathrm{nM}$ glycoprotein (as indicated), or water (W). Only the $50 \mathrm{nM}$ elicitor treatment caused hypersensitive response (HR), observed as visual necrosis. Total RNA was extracted $9 \mathrm{~h}$ after treatment to probe against $O$ methyltransferase (OMT) and 3-hydroxy-3-methylglutarylCoA reductase (HMGR) and $48 \mathrm{~h}$ after treatment to probe against PR-5. Because of extensive necrosis resulting from the HR, no tissue was sampled at $48 \mathrm{~h}$ when the leaves were infiltrated with $50 \mathrm{nM}$ glycoprotein.

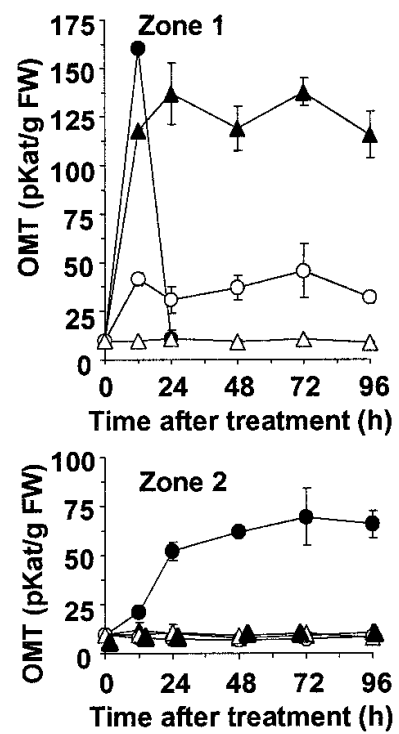

Fig. 4. $O$-methyltransferase (OMT) activity in tobacco leaves infiltrated with either a non-HR (hypersensitive response) or HR dose of elicitor. Leaves were infiltrated with either $0.25 \mathrm{nM}$ (closed triangles) or $50 \mathrm{nM}$ (closed circles) glycoprotein, or water (open circles). OMT activity was measured from infiltrate zone 1, from surrounding zone 2, and from control nontreated leaves (open triangles). Each time point represents the mean of two independent experiments and the standard deviation. compared with that in zone 1 and, as a positive control, defense responses were also analyzed in leaves infiltrated with the HR dose of glycoprotein. Figure 4 shows induced OMT activity in zone 1 , but not in zone 2 , after treatment with 0.25 $\mathrm{nM}$ glycoprotein (closed triangles). In leaves treated with an HR dose of glycoprotein, we measured a strong and transient stimulation of OMT activity in HR zone 1 and a strong and sustained activation in the corresponding LAR zone 2 (Fig. 4, closed circles).

Treatments with a non-HR dose of glycoprotein caused PR protein expression in zone 1 but not in zone 2. Figure 5A shows in situ $\beta$-glucuronidase (GUS) activity in PR-1a-uidA transgenic tobacco plants. A strong GUS activity was detected in zone 1 after infiltration of a non-HR dose of glycoprotein (Fig. 5A). On the other hand, application of an HR dose induced detectable GUS activity only in the surrounding zone 2 (Fig. 5A), and this correlated well with earlier work (Dorey et al. 1997). Analyzing PR proteins by immunodetection, we found a strong accumulation of PR-1, PR-2, PR-3, and PR-5 proteins in zone 1 , but not in zone 2 , of leaves infiltrated with $0.25 \mathrm{nM}$ glycoprotein (Fig. 5B). As a positive control, treatment with $50 \mathrm{nM}$ glycoprotein induced strong PR protein accumulation in LAR zone 2 (Fig. 5B). These results indicated that the non-HR dose of glycoprotein stimulated class I and class II defense responses only in elicitor-infiltrated zone 1.

\section{A non-HR dose of elicitor induces $\mathrm{SA}$ accumulation only in zone 1 .}

Total SA was quantified in zone 1 and zone 2 of leaves infiltrated with a non-HR dose of glycoprotein or, as a positive control, with an HR dose. Three independent experiments were performed and led to similar results. Figure 6 shows the results of a typical experiment. Treatment with either 0.25 or $50 \mathrm{nM}$ glycoprotein resulted in SA accumulation in zone 1 (Fig. 6, closed triangles and circles, respectively). SA levels found in $0.25 \mathrm{nM}$-treated zone 1 were slightly lower than

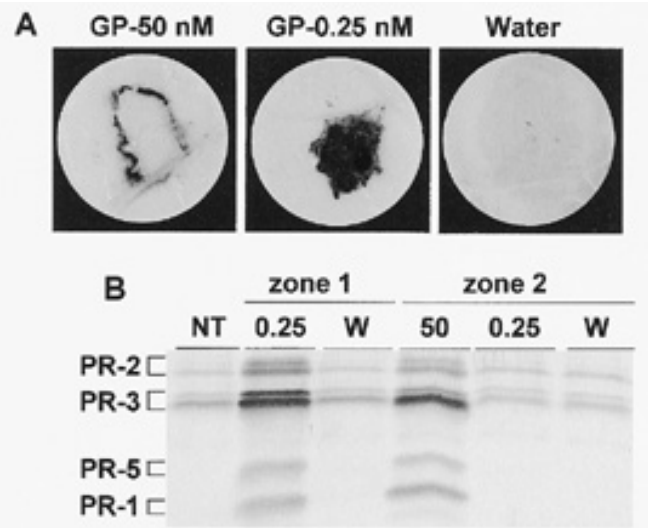

Fig. 5. Pathogenesis-related (PR) proteins in tobacco leaves infiltrated with either a non-HR (hypersensitive response) or a HR dose of elicitor. Leaves were infiltrated with either 0.25 or $50 \mathrm{nM}$ glycoprotein (GP), or water. A, Histochemical localization of $\beta$-glucuronidase (GUS) activity in treated leaves of transgenic PR-1a-uidA xanthi nc plants. GUS staining was performed on leaf disks sampled $48 \mathrm{~h}$ after treatment. B, Immunodetection of PR proteins in treated leaves of Samsun NN plants. Total protein was extracted $72 \mathrm{~h}$ after water (W) or elicitor (as indicated) treatments from infiltrated-zone 1, from surrounding-zone 2 and from nontreated leaves (NT). Immunodetection was performed with a mixture of antibodies raised against PR-1, PR-2, PR-3, and PR-5 proteins. 
those found in $50 \mathrm{nM}$-treated zone 1, but remained elevated for a longer period of time. Analyzing zone 2, we found increased SA amounts only when leaves were infiltrated with the HR dose of glycoprotein (Fig. 6). Similarly to defense response expression, no elevated SA levels could be detected in zone 2 surrounding the tissue infiltrated with the non-HR dose of glycoprotein.

\section{A compound(s) other than $\mathrm{SA}$ is diffusing out of $\mathrm{HR}$ zone 1 to trigger a subset of LAR responses.}

The above results suggested that SA was not diffusing out of the HR zone 1 to LAR zone 2. Indeed, similar SA amounts were found in zone 1 of leaves treated with either the HR dose or the non-HR dose of glycoprotein, while increased SA levels occurred only in LAR zone 2 as a result of the HR-inducing treatment. If SA is the mobile LAR signal, then induction of defense responses in zone 2 of NahG tobacco leaves (Gaffney et al. 1993) treated with an HR dose of elicitor should be suppressed or drastically diminished. Infiltration of $50 \mathrm{nM}$ glycoprotein into NahG leaves induces HR cell death while SA

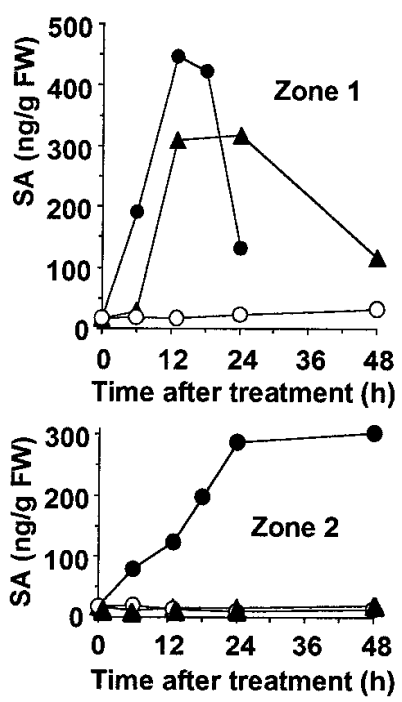

Fig. 6. Salicylic acid (SA) in tobacco leaves infiltrated with either a nonHR (hypersensitive response) or a HR dose of elicitor. Leaves were infiltrated with either $0.25 \mathrm{nM}$ (closed triangles) or $50 \mathrm{nM}$ (closed circles) glycoprotein, or water (open circles). SA was measured from infiltrated zone 1 and from surrounding zone 2 .

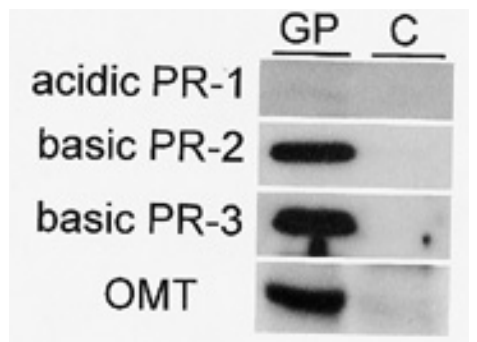

Fig. 7. Defense protein accumulation in zone 2 of $\mathrm{NahG}$ tobacco leaves treated with a hypersensitive response (HR) dose of elicitor. Leaves were infiltrated with $50 \mathrm{nM}$ glycoprotein (GP). Total protein was extracted from zone 2 surrounding the infiltrated zone $1,72 \mathrm{~h}$ after water (C) or GP treatments. Acidic PR-1, basic PR-2, basic PR-3, and $O$-methyltransferase (OMT) were immunodetected. does not accumulate either in the elicitor-infiltrated tissue or in the surrounding tissue (Dorey et al. 1998). Figure 7 shows a strong accumulation of OMT protein and of the basic counterparts of PR-2 and PR-3 while expression of acidic PR-1 is suppressed as expected. Hence, zone 2 exhibited defense responses shown to be expressed during LAR, except the responses controlled by SA, like acidic PR-1, that were suppressed due to NahG gene activity. A signal other than SA is, thus, diffusing from HR zone 1 to LAR zone 2.

\section{A non-HR dose of elicitor does not induce elevated $\mathrm{H}_{2} \mathrm{O}_{2}$ levels.}

$\mathrm{H}_{2} \mathrm{O}_{2}$ was quantified in leaves treated with a non-HR dose or an HR dose of glycoprotein. Several experiments were performed and gave similar results. Figure 8 illustrates the results of a typical experiment. Infiltration of $0.25 \mathrm{nM}$ glycoprotein, as well as water (Fig. 8, closed triangles and open circles, respectively) did not result in increased $\mathrm{H}_{2} \mathrm{O}_{2}$ levels either in zone 1 or zone 2, compared with nontreated tissues (Fig. 8, open triangles). Elevated $\mathrm{H}_{2} \mathrm{O}_{2}$ levels were measured only in zone 1 of leaves infiltrated with $50 \mathrm{nM}$ glycoprotein (Fig. 8, closed circles). Hence, treatment with the non-HR dose of glycoprotein triggers defense responses without measurable elevated $\mathrm{H}_{2} \mathrm{O}_{2}$ levels.

\section{A non-HR dose of elicitor induces enhanced resistance to TMV infection only in zone 1.}

Considering the above results, it was expected that no enhanced resistance to TMV infection would occur in the tissue surrounding the zone infiltrated with a non-HR dose of elicitor. Thus, leaves were infiltrated with $0.20 \mathrm{nM}$ glycoprotein, and 5 days later were inoculated with TMV. Lesion number and diameter were determined 6 days later in the elicitortreated tissue and in the surrounding tissue. Treated zone 1 tissues exhibited lesions that were smaller, but not fewer, than
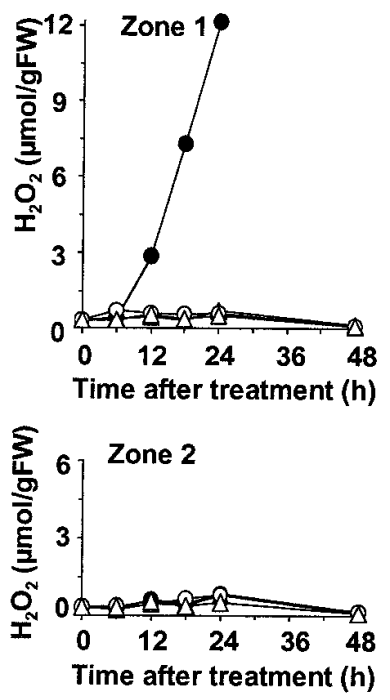

Fig. 8. $\mathrm{H}_{2} \mathrm{O}_{2}$ in tobacco leaves infiltrated with either a non-HR (hypersensitive response) or a HR dose of elicitor. Leaves were infiltrated with either $0.25 \mathrm{nM}$ (closed triangles) or $50 \mathrm{nM}$ (closed circles) glycoprotein, or water (open circles). $\mathrm{H}_{2} \mathrm{O}_{2}$ was measured from infiltrated zone 1 , from surrounding zone 2 , and from nontreated leaves (open triangles). 
those from control water-infiltrated leaves (Fig. 9, zone 1 tissues). The reduction in lesion size was about $50 \%$. There was no difference in size or number between lesions from tissues beyond zone 1 and those from water-treated leaves (Fig. 9). In particular, there was no difference in size between lesions found close to (within $1 \mathrm{~cm}$ ) the elicitor-infiltrated tissues, those found close to the water-infiltrated tissues, and those found beyond this limit after either treatment. In other words, enhanced resistance to TMV infection occurred only within tissue infiltrated with the non-HR dose of elicitor.

\section{DISCUSSION}

Experimental conditions have been defined for which infiltration into tobacco leaves of a fungal glycoprotein, previously described as an HR-inducing elicitor (Baillieul et al. 1995), resulted in induction of enhanced virus resistance and of defense responses without $\mathrm{HR}$ cell death and without an $\mathrm{H}_{2} \mathrm{O}_{2}$ burst. The analyzed defense responses concerned genes and key enzymes (transcripts levels and enzyme activities) of the phenylpropanoid and sesquiterpenoid pathways, PR proteins (transcripts and protein amounts), and levels of the signal SA. None of these defense responses and no enhanced TMV resistance were detectable beyond the elicitor-infiltrated tissue. This contrasted with the strong activation of the same responses in leaf tissue exhibiting LAR (Dorey et al. 1997), and provides strong evidence that there is no LAR in zone 2 when HR is not induced.

Zone 1 and zone 2 tissues can be sampled easily without cross-contaminations. Indeed, infiltration with a syringe allows an accurate control of the leaf tissue in contact with the elicitor, i.e., LAR zone 2 surrounding HR zone 1 remains elicitor-free (Dorey et al. 1997). Analysis at the cellular level now further illustrates the clear-cut demarcation between dead and living cells at the edge between HR zone 1 and LAR zone 2 (Fig. 1).

An important prerequisite of this study was to check that no cell death was induced upon treatment with $0.25 \mathrm{nM}$ gly-

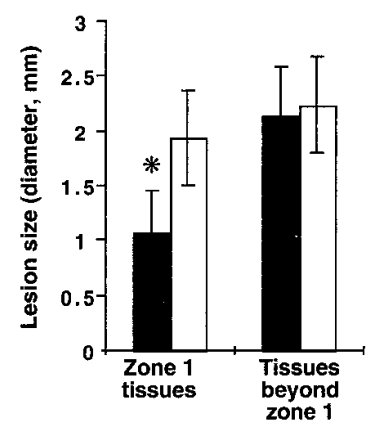

Fig. 9. Enhanced resistance to tobacco mosaic virus infection of tobacco plants treated with a non-HR (hypersensitive response) dose of elicitor. Leaves were infiltrated with either $0.20 \mathrm{nM}$ glycoprotein or water. The treated leaves were inoculated with tobacco mosaic virus (TMV) 5 days later. Lesion size was measured 6 days later. White bars: mean (and standard deviation) of lesion diameters from control water-treated leaves; black bars: mean (and standard deviation) of lesion diameter from elicitor-treated leaves. Diameter of lesions from infiltrated tissues and from tissues beyond infiltrated zone 1 was determined. Diameter of a total of 2,842 lesions was measured with an ocular micrometer. Star indicates the mean, which is significantly different at the $1 \%$ level with Student's $t$ test. coprotein defined as a non-HR dose. This elicitor concentration is 200-fold lower than that routinely used to trigger HR and LAR. Cell death was evaluated visually (tissue necrosis), quantitatively (Evans blue assay), and by in situ analysis (trypan blue assay) (Fig. 2). No increased cell death could be measured by either assay under the defined non-HR condition. In addition, no cell death, resembling the micro-HRs described by Alvarez et al. (1998), was observed 24 h (Fig. 2) and $48 \mathrm{~h}$ (data not shown) after elicitor treatments in LAR tissue and beyond.

Leaves treated with a non-HR dose of elicitor showed enhanced resistance to TMV infection strictly localized to the infiltrated tissues. In other words, there was no effect on lesion size in tissues beyond the infiltrated site. Hence, a treatment with a non-HR dose of elicitor also led to acquired resistance to TMV infection. Thus, acquired resistance was induced after an HR or a non-HR treatment. In the first case, LAR occurs in zone 2 and is triggered by a plant signal(s) diffusing out of HR zone 1, while in the second case, acquired resistance is strictly limited to the elicitor-treated zone 1 and, most probably, no diffusing plant signal is involved in its induction.

The decrease in lesion size in zone 1 after a non-HR treatment was about $50 \%$, compared with controls. Under the same growth chamber conditions, we measured a $20 \%$ decrease in the size of TMV lesions developing on challenged systemic leaves exhibiting SAR induced by a primary hypersensitive TMV infection (data not shown). Enhanced resistance of glycoprotein-treated tissues can be explained by the high levels of defense responses, though among the responses analyzed none was described as specifically antiviral.

There are other examples showing increased resistance to pathogen infection after treatments that do not trigger HR cell death. Tobacco plants treated by deposition of 1 to $5 \mathrm{nmol} \alpha$ elicitins onto decapitated stems displayed protection against Phytophthora parasitica (Bonnet et al. 1996; Kamoun et al. 1993) and Sclerotinia sclerotiorum (Bonnet et al. 1996). $\alpha$ Elicitins are proteins secreted by Phytophthora spp. and are known to diffuse in the plant without inducing visible necrosis. The Arabidopsis $d n d l$ mutant was shown to be defective in HR cell death after infection with different avirulent Pseudomonas syringae strains (Yu et al. 1998). Nevertheless, this mutant restricted bacterial growth, indicating that resistance can occur in the absence of extensive HR cell death. The mutant constitutively expressed elevated levels of SA and of PR1 mRNAs, the latter being increased after pathogen inoculation. Yu et al. (1998) suggested that the constitutive induction of acquired resistance may substitute for HR cell death in potentiating the stronger gene-for-gene response. It should be noted that, in our system, TMV HR lesions are still developing in tissue exhibiting acquired resistance.

The nature of the LAR signal(s) is still unknown. There are several clues that are not in favor of SA being the (or one of the) diffusing LAR signal(s). Previous experiments have shown that most, if not all, of SA found in LAR tissue originates from de novo synthesis (Dorey et al. 1997). Here we show that similar amounts of SA are found in zone 1 infiltrated with a non-HR or an HR dose of elicitor, and that SA accumulates in LAR zone 2 but not in zone 2 of leaves infiltrated with a non-HR dose. Thus, the possibility still exists that very small SA amounts could diffuse out of dead cells of 
HR zone 1 to LAR zone 2. Consequently, either SA would trigger its own synthesis, which is still an open question (Mauch-Mani and Slusarenko 1996), or SA and another signal are acting in combination to trigger LAR. NahG tobacco plants have been engineered to catabolize SA into catechol, and thus do not accumulate SA upon TMV infection (Gaffney et al. 1993) or upon glycoprotein treatment inducing the HR (Dorey et al. 1998). Infiltration of NahG leaves with an HRdose of glycoprotein induced strong defense responses in zone 2. Hence, a signal different from SA is diffusing from HR zone 1 to LAR zone 2, and NahG plants still produce the mobile LAR signal(s). It is noteworthy that NahG plants did not exhibit the full spectrum of defense responses. Expression of acidic PR-1 was suppressed while that of basic PR-2, basic PR-3, and OMT was strongly stimulated, as during LAR induced in Samsun NN plants after glycoprotein treatment (Dorey et al. 1997). This observation indicates that SA is an important transducer for some of the defense responses in tissue exhibiting LAR, though SA itself, most probably, is not diffusing out of the HR zone 1. The possibility of SA diffusion cannot formally be excluded since very low SA levels are still present in NahG plants (Dorey et al. 1998). The fact that NahG tobacco plants are able to mount only a subset of defense responses during LAR, which was assayed molecularly, can explain their diminished capacity to restrict TMV infection (Delaney et al. 1994). Application to tobacco leaves of exogenous SA was shown to trigger acidic PR-1 gene expression but not basic PR-2 and basic PR-3 gene expression (Ward et al. 1991). On the other hand, ethephon (Brederode et al. 1991) and methyljasmonate (Niki et al. 1998) were described as inducers of basic PR-2 and basic PR-3, but not acidic PR-1, in tobacco, and also of phenylalanine ammonia-lyase (PAL) in soybean cell cultures (Gundlach et al. 1992). Whether ethylene and/or methyljasmonate participate in LAR signaling remains an open question. Nitric oxide (NO) is also a putative candidate. Indeed, in tobacco leaves, NO- was shown to trigger PAL gene expression independently of SA (Durner et al. 1998).

$\mathrm{H}_{2} \mathrm{O}_{2}$ is another potential LAR signal. It has been shown to activate PR protein expression (Chamnongpol et al. 1998; Chen et al. 1993), to diffuse from cell-to-cell and induce antioxidant genes (Levine et al. 1994), and to trigger longdistance responses through the local oxidative burst (Alvarez et al. 1998). The fact that a strong $\mathrm{H}_{2} \mathrm{O}_{2}$ increase occurs in our system during $\mathrm{HR}$ (Dorey et al. 1998), while no $\mathrm{H}_{2} \mathrm{O}_{2}$ rise is measured under non-HR treatment, could be in favor of $\mathrm{H}_{2} \mathrm{O}_{2}$ being the (or one of the) LAR signal(s). However, we have shown previously (Dorey et al. 1998) that infiltration into tobacco leaves of glucose oxidase and glucose that generates $\mathrm{H}_{2} \mathrm{O}_{2}$ did not cause increased PR-1 and CAT2 (a catalase enzyme) expression in the surrounding zone 2 tissue and that the co-infiltration of $50 \mathrm{nM}$ glycoprotein and $10 \mu \mathrm{M}$ diphenylene iodonium, shown to inhibit the elicitor-induced $\mathrm{H}_{2} \mathrm{O}_{2}$ burst in cell suspensions, did not suppress or decrease PR-1 and CAT2 expression in LAR zone 2. These results suggested that $\mathrm{H}_{2} \mathrm{O}_{2}$ was not the primary mobile signal diffusing from $\mathrm{HR}$ zone 1 to LAR zone 2.

Modulation of the glycoprotein amounts applied to tobacco leaves also highlighted some features of the signaling pathways involved in defense response expression and in HR cell death. Treatment with a non-HR dose of elicitor induced the same set of defense responses as that observed when an HR dose was used. This finding substantiates a previous observation. Analyzing the defense responses in tissue undergoing $\mathrm{HR}$, we observed that, due to the timing of gene expression and cell death, sustained transcription and translation had time to proceed to some extent for early, class I but not for late, class II defense genes (Dorey et al. 1997). Here we show that, when HR is not induced, the defense response program initiated by the perception of the exogenous fungal signal appears fully executed, at least for those responses analyzed but with the exception of the $\mathrm{H}_{2} \mathrm{O}_{2}$ burst. It is noteworthy that application of $0.25 \mathrm{nM}$ glycoprotein, which is just below the threshold level for HR induction, triggered defense responses with kinetics and amplitude similar to those observed during the 50 $\mathrm{nM}$ glycoprotein-induced HR. A similar observation was reported earlier by Jakobek and Lindgren (1993), who analyzed defense gene transcript accumulation in bean leaves inoculated with different bacteria. They showed that transcript accumulation can occur in the absence of HR cell death in mutant bacteria-infected bean leaves, with kinetics and amplitude similar to those observed during HR caused by the infection with incompatible bacteria. This pointed to a general mechanism for the induction of defense genes that is distinct from a more specific mechanism associated with induction of the HR. Our present results further show that the switch from only defense gene activation to HR cell death induction can be achieved by an increase in the concentration of a single elicitor molecule applied to the plant, suggesting that a threshold seems to be necessary for irrevocable commitment to death. The occurrence of such a threshold has been described in the Arabidopsis $l s d l$ mutant, which exhibits a lowered threshold to trigger HR (Jabs et al. 1996). Taken together, these data strengthen the two hypotheses presented by Morel and Dangl (1997): that the initial signaling pathway can fork into two branches, one leading to defense response expression while the other ends in cell death; and that a threshold seems to be necessary for irrevocable commitment to death. In our system, the threshold is achieved when applying about $1 \mathrm{nM}$ glycoprotein. Below this level there is a dose/response effect of the elicitor as regards PR, OMT, and HMGR gene expression. So far, in our various experimental approaches, LAR in zone 2 could never be uncoupled from cell death, suggesting that LAR is tightly linked to HR cell death.

\section{MATERIALS AND METHODS}

\section{Plant material and treatments.}

Nicotiana tabacum cv. Samsun NN and transgenic PR-1auidA N. tabacum cv. xanthi nc plants (NahG 10 line; Gaffney et al. 1993) were grown in a glasshouse and placed 2 to 3 days before treatment in a growth room at $22 \pm 1^{\circ} \mathrm{C}$ with a photoperiod of $18 \mathrm{~h}$. The glycoprotein was purified from the culture medium of Phytophthora megasperma $\mathrm{H} 20$ as described (Baillieul et al. 1995). The glycoprotein diluted into water was infiltrated into leaves of 3- to 4-month-old tobacco plants to cover areas of 3 to $4 \mathrm{~cm}^{2}$. The infiltrated tissue, called zone 1 , was carefully delineated with a felt-tip marker. Zone 2 corresponds to the 5-mm-width tissue immediately surrounding zone 1. Samsun NN plants were inoculated with the common strain of TMV by rubbing the leaves with an aqueous suspension of highly purified virus $(0.2 \mu \mathrm{g} / \mathrm{ml})$ in the presence of celite. 


\section{Cell death assays.}

Cell death was monitored by two means. A leaf disk assay with Evans blue as the vital dye was performed as described by Baker and Mock (1994). Leaf disks were punched out with a cork borer from three leaves of three plants. One 16-mmdiameter disk was collected from each elicitor-infiltrated zone 1, and five 7-mm-diameter disks were collected from the corresponding zone 2 tissue. For each independent experiment, three zone 1 disks and 15 zone 2 disks were analyzed. The second assay was performed to evaluate cell death in situ and used trypan blue as the vital dye. It was performed according to Koch and Slusarenko (1990).

\section{Protein and GUS in situ assays.}

Protein extracts were made from $150 \mathrm{mg}$ (fresh weight) of tissue sampled as for the Evans blue cell death assay. Samples were ground in $750 \mu \mathrm{l}$ of buffer containing $100 \mathrm{mM}$ sodium phosphate, $\mathrm{pH} 7.5$, charcoal, and quartz. The crude extract was clarified by centrifugation and used for OMT and PR protein analysis. Analysis of OMT activity was performed as described in Pellegrini et al. (1993). Analysis of OMT and PR proteins by immunoblotting was performed as in Baillieul et al. (1995). Protein extracts corresponding to $10 \mathrm{mg}$ (fresh weight) were loaded onto the gels. Antisera to probe PR proteins had been raised against PR-1a, PR-2c, PR-3a, PR-5a, chi32 (basic PR-3), and glucb (basic PR-2). An anti-OMT2 serum was used to probe class II OMT. Histological GUS analysis was performed according to Jefferson et al. (1987).

\section{RNA analysis.}

Total RNA was extracted from 0.5 to $1 \mathrm{~g}$ of plant material. Procedures for extraction and Northern (RNA) hybridization have been described previously (Baillieul et al. 1995). The probes were the tobacco cDNA clones encoding class II OMT (Pellegrini et al. 1993), and PR-5 provided by J. Bol (Leiden) (Brederode et al. 1991), and the cDNA clone (provided by E. Jamet, IBMP, Strasbourg) isolated from Nicotiana sylvestris and encoding HMGR (Genschick et al. 1992). A cDNA clone encoding the 25S rRNA from Capsicum annuum obtained from R. Schantz (IBMP, Strasbourg) was used to normalize the RNA blots.

\section{SA and hydrogen peroxide analysis.}

Extraction from leaf tissues and high-performance liquid chromatography (HPLC) analysis of total SA were performed as already described (Dorey et al. 1997). For each time point, SA was extracted from leaves of three plants, representing six to eight treated zones. For $\mathrm{H}_{2} \mathrm{O}_{2}$ analysis, tissue was sampled as for the Evans blue cell death assay but six zone 1 disks and 30 zone 2 disks were used to analyze $\mathrm{H}_{2} \mathrm{O}_{2}$ for each independent experiment. $\mathrm{H}_{2} \mathrm{O}_{2}$ was extracted from leaf tissue according to Okuda et al. (1991) and analyzed as described by Dorey et al. (1998).

\section{ACKNOWLEDGMENTS}

We are grateful to Rhône-Poulenc, to the CNRS, and to the French Ministry of Education and Research for the financial support of L. C. (CIFRE fellowship granted by Rhône-Poulenc and the French Ministry of Education and Research) and of S. C. (BDI fellowship granted by Rhône-Poulenc and the CNRS). We also thank P. Saindrenan for helpful discussions, and Novartis (USA) for providing seeds of transgenic PR1a-uidA tobacco plants.

\section{LITERATURE CITED}

Alvarez, M. E., Pennell, R. I., Meijer, P., Ishikawa, A., Dixon, R. A., and Lamb, C. 1998. Reactive oxygen intermediates mediate a systemic signal network in the establishment of plant immunity. Cell 92:773784.

Baillieul, F., Genetet, I., Kopp, M., Saindrenan, P., Fritig, B., and Kauffmann, S. 1995. A new elicitor of the hypersensitive response in tobacco: A fungal glycoprotein elicits cell death, expression of defence genes, production of salicylic acid, and induction of systemic acquired resistance. Plant J. 8:551-560.

Baker, C. J., and Mock, N. M. 1994. An improved method for monitoring cell death in cell suspension and leaf disc assays using Evans blue. Plant Cell Tissue Organ Cult. 39:7-12.

Bonnet, P., Bourdon, E., Ponchet, M., Blein, J. P., and Ricci, P. 1996. Acquired resistance triggered by elicitins in tobacco and other plants. Eur. J. Plant Pathol. 102:181-192.

Brederode, F. T., Linthorst, H. J. M., and Bol, J. F. 1991. Differential induction of acquired resistance and PR gene expression in tobacco by virus infection, ethephon treatment, UV light and wounding. Plant Mol. Biol. 17:1117-1125.

Chamnongpol, S., Willekens, H., Moeder, W., Langebartels, C., Sandermann, H., Van Montagu, A., Inze, D., and Van Camp, W. 1998. Defense activation and enhanced pathogen tolerance induced by $\mathrm{H}_{2} \mathrm{O}_{2}$ in transgenic tobacco. Proc. Natl. Acad. Sci. USA 95:5818-5823.

Chen, Z. X., Silva, H., and Klessig, D. F. 1993. Active oxygen species in the induction of plant systemic acquired resistance by salicylic acid. Science 262:1883-1886.

Delaney, T. P., Uknes, S., Vernooij, B., Friedrich, L., Weymann, K., Negrotto, N., Gaffney, T., Gut-Rella, M., Kessmann, H., Ward, E., and Ryals, J. 1994. A central role of salicylic acid in plant disease resistance. Science 266:1247-1250.

Dorey, S., Baillieul, F., Pierrel, M.-A., Saindrenan, P., Fritig, B., and Kauffmann, S. 1997. Spatial and temporal induction of cell death, defense genes, and accumulation of salicylic acid in tobacco leaves reacting hypersensitively to a fungal glycoprotein elicitor. Mol. PlantMicrobe Interact. 10:646-655.

Dorey, S., Baillieul, F., Saindrenan, P., Fritig, B., and Kauffmann, S. 1998. Tobacco class I and II catalases are differentially expressed during elicitor-induced hypersensitive cell death and localized acquired resistance. Mol. Plant-Microbe Interact. 11:1102-1109.

Draper, J. 1997. Salicylate, superoxide synthesis and cell suicide in plant defence. Trends Plant Sci. 2:162-165.

Durner, J., Wendehenne, D., and Klessig, D. F. 1998. Defense gene induction in tobacco by nitric oxide, cyclic GMP, and cyclic ADPribose. Proc. Natl. Acad. Sci. USA 95:10328-10333.

Fritig, B., Heitz, T., and Legrand, M. 1998. Antimicrobial proteins in induced plant defense. Curr. Opin. Immunol. 10:16-22.

Gaffney, T., Friedrich, L., Vernooij, B., Negrotto, D., Nye, G., Uknes, S., Ward, E., Kessmann, H., and Ryals, J. 1993. Requirement of salicylic acid in systemic acquired resistance. Science 261:754-756.

Genschick, P., Criqui, M.-C., Parmentier, Y., Marbach, J., Durr, A., Fleck, J., and Jamet, E. 1992. Isolation and characterization of a cDNA encoding a 3-hydroxy-3-methylglutaryl coenzyme A reductase from Nicotiana sylvestris. Plant Mol. Biol. 20:337-341.

Goodman, R. N., and Novacky, A. J. 1994. The Hypersensitive Reaction in Plants to Pathogens: A Resistance Phenomenon. American Phytopathological Society, St. Paul, MN.

Gundlach, H., Müller, M. J., Kutchan, T. M., and Zenk, M. H. 1992. Jasmonic acid is a signal transducer in elicitor-induced plant cell cultures. Proc. Natl. Acad. Sci. USA 89:2389-2393.

Hammond-Kosack, K. E., and Jones, J. D. G. 1996. Resistance genedependent plant defense responses. Plant Cell 8:1773-1791.

Jabs, T., Dietrich, R. A., and Dangl, J. L. 1996. Initiation of runaway cell death in an Arabidopsis mutant by extracellular superoxide. Science 273:1853-1856.

Jakobek, J. L., and Lingren, P. B. 1993. Generalized induction of defense responses in bean is not correlated with the induction of the hypersensitive response. Plant Cell 5:49-56.

Jefferson, R. A., Kavanagh, T. A., and Bevan, M. W. 1987. GUS fusion: 
$\beta$-Glucuronidase as a sensitive and a versatile gene fusion marker in higher plants. EMBO J. 6:3901-3907.

Kamoun, S., Young, M., Glascock, C. B., and Tyler, B. M. 1993. Extracellular protein elicitors from Phytophthora: Host-specificity and induction of resistance to bacterial and fungal phytopathogens. Mol. Plant-Microbe Interact. 6:15-25.

Koch, E., and Slusarenko, A. 1990. Arabidopsis is susceptible to infection by a downy mildew fungus. Plant Cell 2:437-445.

Kombrink, E., and Somssich, I. E. 1995. Defense responses of plants to pathogens. Adv. Bot. Res. 21:1-34.

Levine, A., Tenhaken, R., Dixon, R., and Lamb, C. 1994. $\mathrm{H}_{2} \mathrm{O}_{2}$ from the oxidative burst orchestrates the plant hypersensitive disease resistance response. Cell 79:583-593.

Mauch-Mani, B., and Slusarenko, A. J. 1996. Production of salicylic acid precursors is a major function of phenylalanine ammonia-lyase in the resistance of Arabidopsis to Peronospora parasitica. Plant Cell 8: 203-212.

Morel, J.-B., and Dangl, J. L. 1997. The hypersensitive response and the induction of cell death in plants. Cell Death Differ. 4:671-683.

Nicholson, R. L., and Hammerschmidt, R. 1992. Phenolic compounds and their role in disease resistance. Annu. Rev. Phytopathol. 30:369-389.

Niki, T., Mitsuhara, I., Seo, S., Ohtsubo, N., and Ohashi, Y. 1998. Antagonistic effect of salicylic acid and jasmonic acid on the expression of pathogenesis-related $(\mathrm{Pr})$ protein genes in wounded mature tobacco leaves. Plant Cell Physiol. 39:500-507.
Okuda, T., Matsuda, Y., Yamanaka, A., and Sagisaka, S. 1991. Abrupt increase in the level of hydrogen peroxide in leaves of winter wheat is caused by cold treatment. Plant Physiol. 97:1265-1267.

Pellegrini, L., Geoffroy, P., Fritig, B., and Legrand, M. 1993. Molecular cloning and expression of a new class of ortho-diphenol- $O$ methyltransferases induced in tobacco (Nicotiana tabacum L.) leaves by infection or elicitor treatment. Plant Physiol. 103:509-517.

Ross, A. F. 1961a. Localized acquired resistance to plant virus infection in hypersensitive hosts. Virology 14:329-339.

Ross, A. F. 1961b. Systemic acquired resistance induced by localized virus infections in plants. Virology 14:340-358.

Ryals, J. A., Neuenschwander, U. H., Willits, M. G., Molina, A., Steiner, H. Y., and Hunt, M. D. 1996. Systemic acquired resistance. Plant Cell 8:1809-1819.

Schneider, M., Schweizer, P., Meuwly, P., and Métraux, J. P. 1996. Systemic acquired resistance in plants. Int. Rev. Cytol. 168:303-339.

Stoessl, A., Stothers, J. B., and Ward, E. W. B. 1976. Sesquiterpenoid stress compounds of the Solanaceae. Phytochemistry 15:855-872.

Ward, E., Uknes, S., Williams, S., Dincher, S., Wiederhold, D., Alexander, D., Ahl-Goy, P., Metraux, J. P., and Ryals, J. 1991. Coordinate gene activity in response to agents that induce systemic acquired resistance. Plant Cell 3:1085-1094.

Yu, I. C., Parker, J., and Bent, A. F. 1998. Gene-for-gene disease resistance without the hypersensitive response in Arabidopsis dndl mutant. Proc. Natl. Acad. Sci. USA 95:7819-7824. 